\title{
Minimum wages and poverty with income-sharing
}

\author{
Gary S. Fields • Ravi Kanbur
}

\begin{abstract}
Textbook analysis tells us that in a competitive labor market, the introduction of a minimum wage above the competitive equilibrium wage will cause unemployment. This paper makes three contributions to the basic theory of the minimum wage. First, we analyze the effects of a higher minimum wage in terms of poverty rather than in terms of unemployment. Second, we extend the standard textbook model to allow for incomesharing between employed and unemployed persons in society. Third, we extend the basic model to deal with income sharing within families. We find that there are situations in which a higher minimum wage raises poverty, others where it reduces poverty, and yet others in which poverty is unchanged. We characterize precisely how the poverty effect depends on four parameters: the degree of poverty aversion, the elasticity of labor demand, the ratio of the minimum wage to the poverty line, and the extent of income-sharing. Thus, shifting the perspective from unemployment to poverty leads to a considerable enrichment of the theory of the minimum wage.
\end{abstract}

Key words minimum wage $\cdot$ poverty $\cdot$ unemployment

JEL Codes D6 $132 \cdot \mathrm{J} 3 \cdot \mathrm{J} 64$

\section{Introduction}

How does a change in the minimum wage affect economic well-being? The standard economists' argument is that a higher minimum wage is problematical, because it increases unemployment. Minimum wages are typically evaluated in terms of their effects on 
unemployment, be it in standard textbook models [6], in specialized labor market models $[7,10,12,15,16]$, or in empirical studies $[4,5,19]$.

Evaluations based on unemployment implicitly use social welfare functions of the form $W=f(\mathrm{UNEM}), f^{\prime}<0$. In our view, this function is too scanty. A central rationale for minimum wage legislation is that it helps lift the working poor out of poverty by raising their wages. With this argument in mind, in this paper we use a welfare function of the form $W=g(\mathrm{POV}), g^{\prime}<0$, and ask: how does an increase in the minimum wage affect poverty?

Empirical studies relating minimum wages to poverty produce conflicting results. For the US, Card and Krueger [4] find some reductions in poverty as a result of the minimum wage, while Brown [2] finds that minimum wage increases compress the wage distribution. On the other hand, Neumark and Wascher [20] and Adams and Neumark [1] find opposing forces with small net effects. Freeman [9] presents a broader review of the evidence on distributional consequences and of the conflicting tendencies. For Latin America, Morley [17] finds that poverty falls as the minimum wage rises. Using cross-country data on developing countries, McLeod and Lustig [14] also find that a higher minimum wage is associated with lower poverty even though the higher minimum wage reduces employment. Finally, for the case of Brazil, Neumark, Cunningham, and Siga [18] find no evidence that minimum wages in that country lift family incomes in the lower part of the income distribution.

Despite this (albeit scattered) empirical evidence that higher minimum wages could reduce poverty, the tradeoff between reduced poverty among the working poor versus increased poverty because of greater unemployment, has not been addressed in the theoretical literature in precise terms. The first contribution of this paper is to develop a framework where this tradeoff can be assessed in rigorous fashion using a specific family of poverty measures.

Throughout this analysis, poverty is measured using a fixed poverty line $z$ and gauged relative to $z$ using the class of indices developed by Foster, Greer, and Thorbecke [8]. The FGT index, denoted $P_{\alpha}$, takes each poor person's poverty deficit as a percentage of the poverty line, raises it to a power $\alpha$, and averages over the entire population. Letting $y_{i}$ be the income of the $i$ th person, $z$ the poverty line, $q$ the number of poor persons, and $n$ the total number of persons, the $P_{a}$ poverty measure is:

$$
P_{\alpha}=\frac{1}{n} \sum_{i=1}^{q}\left(\frac{z-y_{i}}{z}\right)^{\alpha} .
$$

As is well known, when $\alpha=0$ this measure collapses to the Headcount Ratio, the fraction of people below the poverty line. Other values for $\alpha$ are greater than or equal to one. Benchmark values in this range are $\alpha=1$, in which case we have the Income Gap measure of poverty, and $\alpha=2$, which is known as the Squared Income Gap measure. The higher is $\alpha$, the greater is the sensitivity of poverty to changes in the incomes of the poorest compared to the incomes of the not so poor. For these reasons, $\alpha$ is known as the "poverty aversion" parameter. To allow for the social loss from poverty to increase at an increasing rate as incomes fall relative to the poverty line, it is common for empirical poverty researchers to choose $\alpha=2$. Different degrees of poverty aversion will be seen to be important in delineating the consequences of the minimum wage for poverty.

Unemployment is only one of the factors that breaks any simple relationship between the labor earnings of those employed on the one hand and the incomes of all members of socicty on the other. Income-sharing in families and communities, which typically comprise wage earners and unemployed, can make the distribution of income among individuals very different from that among wage-earners. Empirical estimates of the contribution of a minimum wage to the poverty status of the families of minimum wage workers in the US 
may be tound in Burkhauser, Couch, and Wittenburg [3] and Neumark and Wascher [19]. Further evidence on income-sharing among employed and unemployed members of a family is available for South Africa, for example, in Klasen and Woolard [13]. The second contribution of this paper is to examine theoretically how alternative sharing mechanisms in a society condition the impact of minimum wages on poverty.

Our task in this paper is to use a number of theoretical models to show conditions under which a higher minimum wage raises poverty and when it does not. Throughout the paper, it is assumed that the minimum wage applies and is equally enforced throughout all sectors of the economy. We begin in Section 2 with the textbook model of a competitive labor market. We then proceed to extend the textbook model to allow for two types of incomesharing. In Section 3, the sharing is between employed and unemployed persons in society; we term this the "social sharing model." By contrast, Section 4 extends the textbook model to two-person families, assuming full income-sharing between those family members who are employed and any family members who may be unemployed; we term this the "family sharing model." Table I summarizes the main results of Sections 2, 3, and 4. Section 5 concludes.

\section{Minimum wage and poverty: individuals in a competitive labor market}

Consider the basic textbook labor market model in which a single homogenous type of labor is supplied by workers and demanded by firms. Let the demand for labor be $D(w)$, $D^{\prime}(w)<0$, where $w$ is the wage per period. Assume no labor force entry or exit and normalize the working population at size 1 . Then, with full market-clearing, the nonintervention wage is given by $w^{*}$, where $D\left(w^{*}\right)=1$. Denote the minimum wage by $\widehat{w}$ and assume that this minimum wage applies equally to all jobs in the economy. Given the preceding demand for labor function, a minimum wage reduces employment. The resultant amount of employment, denoted $x$, is $x=D(\widehat{w})$, and the amount of unemployment is $1-x$. The employed get wage income $\widehat{w}$. There is assumed to be no unemployment insurance, so the unemployed get income zero.

We have several cases depending on where the minimum wage $\widehat{w}$ is set relative to the poverty line $z$, and what value is chosen for $\alpha$. Let us start with the case where the minimum wage is set above the poverty line, the object being to raise the working poor out of poverty. In this case, with $0<z \leq \widehat{w}$, all those who work are out of poverty and the unemployed are in it. This corresponds most closely to the conventional theory's identification of unemployment, and only unemployment, with poverty. Since a higher minimum wage will increase unemployment in the textbook model, it follows that in this case it will increase poverty too. More precisely, the $P_{a}$ poverty index in this case is

$$
P_{\alpha}=(1-x)\left(\frac{z-0}{z}\right)^{\alpha}=1-x
$$

for all $\alpha$. When the minimum wage is raised, the effect on $P_{\alpha}$ is

$$
\frac{\mathrm{d} P_{\alpha}}{\mathrm{d} \widehat{w}}=-\frac{\mathrm{d} x}{\mathrm{~d} \widehat{w}}=-D^{\prime}(\widehat{w})>0
$$

Thus if a minimum wage is higher than the poverty line, further increases will increase poverty. But what about the range where the minimum wage is below the poverty line, as it is for example in the United States - in other words, $0<\widehat{w}<z$ ? The poverty population 
Textbook model with no income-sharing

Case where $0<z \leq \widehat{w}$ :

Case where $0<\widehat{w}<z$ :

$$
\alpha=0
$$

$\alpha=1$

$\alpha>1$

The social sharing model

$$
\begin{aligned}
& \text { Case where } x b \hat{w}<z<\widehat{w}[1-b(1-x)] \text { : } \\
& \alpha=0 \\
& \alpha \geq 1
\end{aligned}
$$

Case where $x b \widehat{w}<\widehat{w}[1-b(1-x)]<z$ :

$$
\begin{aligned}
& \alpha=0 \\
& \alpha=1 \\
& \alpha>1
\end{aligned}
$$

The family sharing model

Case where $0<z \leq \frac{1}{2} \widehat{w}$ :

Case where $\frac{1}{2} \widehat{w}<z<\widehat{w}$ :

$$
\begin{aligned}
& \alpha=0 \\
& \alpha \geq 1
\end{aligned}
$$

Case where $0<\widehat{w}<z$ :

$$
\alpha=0
$$$$
\alpha=1
$$

$\alpha>1$
Poverty increases.

Poverty is unchanged.

Poverty increases (decreases) if $\eta$ is greater (less than) one.

Poverty increases (decreases) if $\eta$ is sufficiently high (low) and/or $\alpha$ is sufficiently low (high).

Poverty increases.

Poverty increases (decreases)

if $\eta$ is sufficiently high (low)

Poverty is unchanged.

Poverty increases (decreases)

if $\eta$ is greater (less than) one.

Poverty increases (decreases)

if $\eta$ is sufficiently high (low)

and/or $\alpha$ is sufficiently low (high).

Poverty increases.

Poverty increases.

Poverty increases (decreases)

if $\eta$ is sufficiently high (low).

Poverty is unchanged, because everyone is always poor.

Poverty increases (decreases)

if $\eta$ is greater than (less than) one.

Poverty increases (decreases)

if $\eta$ is sufficiently high (low).

then consists of $x$ poor people who receive the minimum wage $\widehat{w}$ and $1-x$ poor people who are unemployed and receive zero. The extent of poverty in this case is

$$
P_{\alpha}=(1-x)+x\left(\frac{z-\widehat{w}}{z}\right)^{\alpha} .
$$

Various subcases are useful to consider. When $\alpha=0$, the poverty measure is the headcount ratio. The tradeoff between the incomes of the working and non-working poor is not present since with this parameter value what matters is whether a person is poor, not how poor the person is. But everyone is below the poverty line and so the headcount ratio is $100 \%$ and stays that way as the minimum wage changes in this range. Thus:

$$
P_{0}=1
$$


and

$$
\frac{\mathrm{d} P_{0}}{\mathrm{~d} \widehat{w}}=0
$$

Thus, in order for the tradeoff in poverty between the working poor and the non-working poor to bite, we need to consider the range $\alpha \geq 1$. In this case, the extent of poverty is given by Eq. 4 . The effect of a higher minimum wage is found by differentiating Eq. 4 with respect to $\widehat{w}$. Denoting the (local) absolute value of the wage elasticity of demand for labor by $\eta$ and rearranging, we obtain

$$
\frac{\mathrm{d} P_{\alpha}}{\mathrm{d} \widehat{w}}=\frac{x}{\widehat{w}}\left[\eta\left\{1-\left(1-\frac{\widehat{w}}{z}\right)^{g z}\right\}-\alpha \frac{\widehat{w}}{z}\left(1-\frac{\widehat{w}}{z}\right)^{\alpha-1}\right] .
$$

From this it follows that

$$
\frac{\mathrm{d} P_{\alpha}}{\mathrm{d} \widehat{w}}<0 \Leftrightarrow \eta>\frac{\alpha \frac{\widehat{w}}{z}\left(1-\frac{\widehat{w}}{z}\right)^{\alpha \cdots 1}}{1-\left(1-\frac{\widehat{w}}{z}\right)^{\alpha}} .
$$

The condition given in Eq. 8 simplifies as follows for $\alpha=1$ :

$$
\frac{\mathrm{d} P_{\alpha}}{\mathrm{d} \widehat{w}}<0 \Leftrightarrow \eta \eta_{<}^{>}
$$

Thus, in the case $\alpha=1$, poverty increases with the minimum wage if the demand for labor is elastic and decreases if the demand for labor is inelastic. The intuition behind this result is straightforward. When $\alpha=1$, what matters for poverty is the sum of the differences of income from the poverty line for the poor. The income of the unemployed stays fixed at zero, while the total income of the employed falls or rises depending on whether the elasticity of labor demand is greater than or less than unity. Hence the result.

When $\alpha=2$, there is a different critical value of $\eta$ :

$$
\frac{\mathrm{d} P_{\alpha}>}{\mathrm{d} \widehat{w}}<0 \Leftrightarrow \eta_{<}^{>} \frac{2\left(1-\frac{\widehat{w}}{z}\right)}{2-\frac{\widehat{w}}{z}} .
$$

Note that the right hand side of Eq. 10 is decreasing in $\frac{\widehat{w}}{z}$. Thus, for a given $\eta$, a higher $\frac{\widehat{w}}{z}$ makes it more likely that $\frac{d P_{\alpha}}{\widehat{d w}}>0$.

Expressions Eq. 8, 9, and 10 highlight the precise role of the labor demand elasticity in adjudicating the tradeoff between the poverty of the working and non-working poor as the minimum wage is raised. Specifically, poverty increases with the minimum wage when the elasticity of labor demand is sufficiently high, since a sufficiently large amount of additional unemployment is created to overwhelm the opposite force of an improvement in the standard of living of the working poor. The opposite is true when the labor demand elasticity is sufficiently low. How low? The critical value depends on the poverty aversion parameter. For $\alpha=1$, the critical value is unity (see Eq. 9). Since most empirical estimates of labor demand elasticities are indeed between 0 and 1 ( $81 \%$ according to a comprehensive survey by Hamermesh [11], Table 3.2), this condition says that poverty so measured is likely to fall as the minimum wage increases while staying below the poverty line.

But as the concern for the poorest of the poor grows, as in the case $\alpha=2$, this critical value of the labor demand elasticity falls to below unity. Thus, for example, if the minimum wage is $3 / 4$ of the poverty line, from Eq. 10 , the critical value of the labor demand elasticity 
1s 11.4 . Estimated elasticities trequently exceed this $[11 \mathrm{~J}$, with the result that at this level of the minimum wage, further increases will raise poverty as measured by the $P_{\alpha}$ index with $\alpha=2$. But if the minimum wage is only $1 / 2$ of the poverty line, then the critical value of $\eta$ is $2 / 3$, which is in the range of empirical labor elasticity estimates.

The conclusions we have reached on the poverty effects of a higher minimum wage in the textbook model are rich in their empirical and policy implications. If the minimum wage is above the poverty line, further increases will raise poverty. But if the minimum wage is below the poverty line, then the impact on poverty of increasing the minimum wage depends neatly on two observable parameters and one value judgment parameter. The observable parameters are the labor demand elasticity and the ratio of the minimum wage to the poverty line, while the value judgment is captured in the poverty aversion parameter. Our analysis shows the precise configurations of these three parameters such that an increase in the minimum wage will, or will not, reduce poverty.

\section{The social sharing model}

One feature of cconomies is the sharing of income between employed and unemployed members of society. The poorer the country, the more pervasive income-sharing appears to be. To the best of our knowledge, income-sharing has not until now been integrated into theoretical minimum wage models. At one extreme is perfect income-sharing. In this case, income per person is simply the per capita wage bill. Hence, poverty increases or decreases with the minimum wage according to whether the wage elasticity of demand for labor $\eta$ is greater or less than one in absolute value. At the other extreme is zero income-sharing. That case was analyzed in Section 2.

In between perfect income sharing and zero income-sharing is partial income-sharing among employed and unemployed members of society, which is the subject of this section. Let the ith worker's pre-sharing income be denoted by $y$, which is the wage per hour $w$ multiplied by the number of hours worked. Let $y^{*}$ denote that worker's post-sharing income. We suppose that an employed worker pays a "marginal tax" at rate $b$, which finances a fixed income grant of $a$ for all including the employed themselves. In a rich country context, an example of such a system would be a universal family allowance program financed by a proportional payroll tax. In a poor country context, an example would be a "tax" on employed persons, the proceeds of which are used to supplement the contents of the community cooking pot, from which all partake.

With such a program of social sharing, the pre- and post-sharing incomes are related to one another by the relationship

$$
y^{*}=a+(1-b) y .
$$

Before a minimum wage, all workers are employed and receiving the same income, so there is no sharing. When a minimum wage is imposed at level $\widehat{w}$, the pre-sharing income distribution is

$$
\begin{aligned}
y & =\widehat{w} \text { for } x \text { employed workers, } \\
& =0 \text { for } 1-x \text { unemployed workers. }
\end{aligned}
$$

After sharing, the income distribution is

$$
\begin{aligned}
y^{*} & =a+(1-b) \widehat{w} \text { for } x \text { employed workers, } \\
& =a \text { for } 1-x \text { unemployed workers. }
\end{aligned}
$$


Selt-tınancing of the transter among workers requires that

$$
x \widehat{w}=(1-x) a+x[a+(1-b) \widehat{w}],
$$

from which it follows that

$$
a=x b \widehat{w}
$$

Then post-sharing income is given by

$$
\begin{aligned}
y^{*} & =\widehat{w}[1-b(1-x)] & & \text { for the employed } \\
& =x b \hat{w} & & \text { for the unemployed }
\end{aligned}
$$

The zero-sharing and perfect-sharing cases are given by $b=0$ and $b=1$, respectively.

As before, let the poverty line be $z$ and the poverty index be $P_{\alpha}$. In the previous section the income of the unemployed was zero, so they were in poverty for any positive poverty line. With income-sharing, the possibility arises that the poverty line is so low that nobody is in poverty:

$$
z<x b \widehat{w}<\widehat{w}[1-b(1-x)]
$$

In this case there is no poverty, and small changes in the minimum wage do not change poverty at all.

As the poverty line rises, we come to a range where the unemployed are in poverty despite the transfers they receive, but the employed are not in poverty:

$$
x b \widehat{w}<z<\widehat{w}[1-b(1-x)] .
$$

Accordingly, the extent of poverty in the economy is

$$
P_{\alpha}=(1-x)\left(1-\frac{b x \widehat{w}}{z}\right)^{\alpha}
$$

Note that when $b=0$, Eq. 15 collapses to Eq. 2 .

We turn now to various subcases. When $\alpha=0$, what matters is the number of the poor, not their incomes. Hence income-sharing does not affect poverty so measured. What matters is the increase in unemployment as the result of the increased minimum wage. In this subcase $P_{0}=(1-x)$,

$$
\frac{\mathrm{d} P_{0}}{\mathrm{~d} \widehat{w}}=-\frac{\mathrm{d} x}{\mathrm{~d} \widehat{w}}>0
$$

and poverty increases with the minimum wage.

With $\alpha \geq 1$ the minimum wage affects poverty as follows:

$$
\frac{\mathrm{d} P_{\alpha}}{\mathrm{d} \widehat{w}}=\frac{x}{\widehat{w}}\left[\eta\left(1-\frac{b x \widehat{w}}{z}\right)^{\alpha}+(1-x) \alpha \frac{b}{z} \widehat{w}(\eta-1)\left(1-\frac{b x \widehat{w}}{z}\right)^{\alpha-1}\right] .
$$

As in the no income-sharing case, there is also a possible tradeoff. As the minimum wage rises, the number of poor increases and poverty rises on this account; this effect is captured by the first term in square brackets in Eq. 17. But the incomes of the (non-poor) employed also change and so, with sharing, do the incomes of the (poor) unemployed. The impact depends crucially on whether the total income of the employed increases or decreases since, with the self financing constraint, this is the pool of resources that is being redistributed. Hence the importance of the magnitude of the elasticity of labor demand relative to unity, 
which is captured in the second term in the square bracket in $\mathrm{Eq} .1 \%$ Une result that follows immediately is that

$$
\eta \geq 1 \Rightarrow \frac{\mathrm{d} P_{\alpha}}{\mathrm{d} \widehat{w}}>0
$$

i.e., a higher minimum wage increases poverty when the demand for labor is elastic. This is not surprising. When the demand for labor is elastic, an increase in the minimum wage lowers the wage bill, thereby reducing the (transfer) income of the unemployed while increasing their numbers.

So the interesting tradeoff case is when $\eta<1$, i.e., the demand for labor is inelastic. In this case we can derive:

$$
\frac{\mathrm{d} P_{\alpha}}{\mathrm{d} \widehat{w}}<0 \Leftrightarrow \frac{\eta}{1-\eta}<\frac{(1-x) \alpha \frac{\widehat{b \hat{w}}}{z}}{\left(1-\frac{b x \widehat{w}}{z}\right)} .
$$

Equation 19 thus gives us critical values of the labor demand elasticity below which an increase in the minimum wage (in this case, where only the unemployed are poor) will reduce poverty. Some further insight can be derived from special cases. If we start at the market-clearing wage $w^{*}$, there is full employment, i.e., $x=1$. A minimum wage $\widehat{w}$ slightly higher than $w^{*}$ imposed at this point starts with $x=1$, and therefore the numerator of the right hand side of Eq. 19 equals zero. Given that we are working with the inelastic subcase $0<\eta<1$,

$$
\frac{\eta}{1-\eta}>0 \Rightarrow \frac{\mathrm{d} P_{\alpha}}{\mathrm{d} \widehat{w}}>0
$$

Thus, starting at market-clearing, when the demand for labor is inelastic, a small minimum wage increases poverty.

The results so far are can be compared to the textbook case in the previous section where only the unemployed were poor and there was no income-sharing. There, with Eq. 3 we found that an increase in the minimum wage always increased poverty because it increased unemployment. Now we have to set against that force the force of income-sharing by the now better-off employed. So poverty reductions are now possible, but they will not happen for small increments around the market-clearing wage, and outside this neighborhood they will happen only if the elasticity of labor demand is low enough. The critical value is given in Eq. 19. Notice one thing, however. The critical value also depends on the poverty aversion parameter, $\alpha$. If the income of the poorest of the poor matters sufficiently in our value judgments, then a minimum wage will reduce poverty for labor demand elasticities in the empirically plausible range.

Let us finally turn to the case where the poverty line is so high that both the employed and the unemployed are poor:

$$
x b \widehat{w}<\widehat{w}[1-b(1-x)]<z,
$$

We saw in the previous section the playing out of the tradeoff between the poverty of the working poor and the poverty of the unemployed. The same tradeoff will be in play here, but mediated by income-sharing. The amount of poverty in this case is given by

$$
P_{\alpha}=(1-x)\left(1-\frac{b x \widehat{w}}{z}\right)^{\alpha}+x\left(1-\frac{\widehat{w}[1-b(1-x)]}{z}\right)^{\alpha},
$$


which corresponds to Eq. 4 in the no income-shanng case. Notice that Eq. 21 collapses to Eq. 4 when $b=0$.

Some basic intuitions from the earlier discussion still hold in this case. If the elasticity of labor demand exceeds unity, then the total wage bill falls at the same time as the number of the very poorest (the unemployed) increases. Poverty must therefore rise for any value of $\alpha$. When the elasticity of labor demand is less than unity, then all incomes rise but the numbers of the very poorest rise as well. If $\alpha=1$, then what matters is simply the total poverty gap, irrespective of how it is divided among the employed and the unemployed. Thus poverty will fall. But when $\alpha$ exceeds 1 , then with successive increases in $\alpha$, greater and greater weight is put on the well-being of the unemployed relative to the employed. For any given degree of partial sharing it must therefore be the case that an increase in the minimum wage will raise poverty for $\alpha$ high enough.

\section{The family sharing model}

For the analysis of this section, we have individuals living in families. Suppose that each family consists of two individuals, each of whom is a potential earner. Conceptually, poverty is a function of individuals' levels of consumption. In practice, however, empirical researchers rarely know what individual family members consume. Accordingly, for this analysis, poverty is defined as a function of per capita family income, not individual consumption. The poverty line in this economy is an income of $z$ per capita.

As before, employment $x$ is given by the demand function $x=D(\widehat{w})$, where $\widehat{w}$ is the minimum wage. Normalizing the population size at unity, $x$ is also the employment rate. Denote $\frac{d x}{d w}=D^{\prime}(\widehat{w})<0$ and assume a constant elasticity of labor demand $\eta \equiv-\frac{\widehat{w}}{x} \frac{d x}{d w}$.

Let each potential earner in this economy have the same chance as any other of being employed at the minimum wage $\widehat{w}$ with probability $x$ and unemployed with probability $1-$ $x$. The distribution of income in the economy is then as follows:

Some families have both members employed. These families earn (and consume) $2 \widehat{w}$, or $\widehat{w}$ per capita. The number of individuals in such families is $x^{2}$.

Some families have one member employed. These families earn (and consume) $\widehat{w}$, or $\frac{1}{2} \widehat{w}$ per capita. The number of individuals in such families is $2 x(1-x)$.

Some families have both members unemployed. These families earn (and consume) zero. The number of individuals in such families is $(1-x)^{2}$.

There are three cases to consider, depending on where the poverty line is relative to the minimum wage. Case $A$ is where the poverty line is so low that any family with at least one employed member is above the poverty line - that is, $0<z<\frac{1}{2} \widehat{w}$. Case $B$ is where the poverty line is at an intermediate level such that families with one employed member are below the poverty line while those with both members employed are above the poverty line - that is, $0<\frac{1}{2} \widehat{w}<z<\widehat{w}$. Case $C$ is where the poverty line is so high that all families are poor - that is, $0<\widehat{w}<z$.

Again using the $P_{\alpha}$ index to measure poverty, the extent of poverty in the three cases is given by:

$$
\begin{aligned}
& \text { Case A: } P_{\alpha}=(1-x)^{2} . \\
& \text { Case B: } \quad P_{\alpha}=(1-x)^{2}+2 x(1-x)\left[\frac{z-\frac{1}{2} \widehat{w}}{z}\right]^{\alpha} .
\end{aligned}
$$




$$
\text { Case C: } \quad P_{\alpha}=(1-x)^{2}+2 x(1-x)\left[\frac{z-\frac{1}{2} \widehat{w}}{z}\right]^{u}+x^{2}\left[\frac{z-\widehat{w}}{z}\right]^{\alpha} \text {. }
$$

Let us now analyze the effect of a higher minimum wage in each of these three cases.

\subsection{Case A}

The analysis in this case is straightforward:

$$
\frac{\mathrm{d} P_{\alpha}}{\mathrm{d} \widehat{w}}=-2(1-x) \frac{\mathrm{d} x}{\mathrm{~d} \widehat{w}}>0 .
$$

Poverty increases when the minimum wage does. This is because a higher minimum wage raises unemployment and, in this case, the only poor households are those with both members unemployed, the number of which is now greater.

\subsection{Case $B$}

After some manipulation, one obtains, in this case,

$$
\frac{\mathrm{d} P_{\alpha}}{\mathrm{d} \widehat{w}}=2 \eta \frac{x}{\widehat{w}}\left[(1-x)-(1-2 x) \theta^{\alpha}\right]-x(1-x) \frac{\alpha}{z} \theta^{\alpha-1},
$$

where

$$
\theta \equiv\left[1-\frac{\frac{1}{2} \widehat{w}}{z}\right]
$$

To sign the expression in Eq. 26, note two things. First, $\frac{1}{2}>\theta>0$. Second, given that $\theta<1$, we have that $(1-2 x) \theta^{\alpha}<(1-2 x)<(1-x)$ for all $\alpha>1$. Thus, the expression in square brackets in Eq. 26 is positive. Noting that $\frac{1}{\frac{2}{2} \widehat{w}}=1-\theta$ and solving for the critical value of $\eta$, we get for Case B:

$$
\frac{\mathrm{d} P_{\alpha}}{\mathrm{d} \widehat{w}}<0 \Leftrightarrow \eta_{<}^{>} \frac{(1-x) \alpha(1-\theta) \theta^{\alpha-1}}{\left[x \theta^{\alpha}+(1-x)\left(1-\theta^{\alpha}\right)\right]} \equiv K .
$$

Equation 28 gives the general result. For specific values of $\alpha$, the following results are readily derived:

When $\alpha=0$ (i.e., the poverty measure used is the poverty headcount ratio), $K=0$. Given that $\eta>0$, it follows that $\eta>K$ and therefore $\frac{d P_{\alpha}}{d w}>0$ i.e., the headcount ratio rises with the minimum wage.

When $\alpha=1$, the critical value $K$ is given by

$$
K_{1}=\frac{(1-x)(1-\theta)}{[x \theta+(1-x)(1-\theta)]}<1 .
$$

Thus, labor demand has to be sufficiently elastic (inelastic), the critical value given by Eq. 28, for poverty to increase (decrease) when the minimum wage rises. Eqs. 29 and 27 together give the critical value as a function of $x, \widehat{w}$, and $z$.

Finally, when $\alpha=2$, the critical value $K$ is given by

$$
K_{2}=\frac{2(1-x)(1-\theta) \theta}{\left[x \theta^{2}+(1-x)\left(1-\theta^{2}\right)\right]} .
$$


I he denominator of $\mathrm{Fq} .30$ can be rewritten as

$$
x \theta^{2}+(1-x)\left(1-\theta^{2}\right)=2(1-x)(1-\theta) \theta+x \theta^{2}+(1-x)(1-\theta)^{2},
$$

which is the numerator of Eq. 30 plus two additional positive terms. Thus, in this subcase as well, labor demand has to be sufficiently elastic (inelastic) for poverty to increase (decrease) when the minimum wage rises. Expressed as a function of $x, \widehat{w}$, and $z$, the critical value may be found by combining Eqs. 30 and 27 .

We may also analyze how the critical value $K_{\alpha}$ changes with $\alpha$. First, for integer values of $\alpha$, it may be shown that

$$
K_{1}>K_{2} \Leftrightarrow\left(\frac{1-\theta}{\theta}\right)^{2}>\left(\frac{x}{1-x}\right)
$$

both of which are possible. Second, for general values of $\alpha$, the corresponding condition is

$$
\frac{\partial K}{\partial \alpha}>0 \Leftrightarrow \frac{1+\alpha \log \theta}{\theta^{\alpha}}<\frac{1-2 x}{x},
$$

both of which are also possible. Thus, we conclude that a higher value of the poverty aversion parameter $\alpha$ has an ambiguous effect on the critical labor demand elasticity above (below) which an increase in the minimum wage raises (lowers) poverty.

\subsection{Case C}

This case has simple conclusions for $\alpha=0$ and for $\alpha=1$. For $\alpha=0$ (i.e., the poverty measure is the poverty headcount ratio), everyone is always poor and therefore $\frac{\mathrm{d} p_{x}}{d w}=0$ For $\alpha=1$ (i.e., the normalized average income shortfall), since everyone is poor, all that matters is total labor income, not its distribution. Thus $\frac{\mathrm{d} p_{x}>}{\mathrm{d} w}<0 \Leftrightarrow \eta>1$. Finally, for $\alpha>1$, the change in poverty with respect to an increase in the minimum wage is given by

$$
\begin{aligned}
\frac{\mathrm{d} P_{\alpha}}{\mathrm{d} \widehat{w}}- & 2 \eta \frac{x}{\widehat{w}}\left[-(1-x)+(1-2 x) \theta^{\alpha}+x(2 \theta-1)^{\alpha}\right] \\
& -\left[x(1-x) \frac{\alpha}{z} \theta^{\alpha-1}+x^{2} \frac{\alpha}{z}(2 \theta-1)^{\alpha-1}\right] .
\end{aligned}
$$

From this, we get

$$
\frac{\mathrm{d} P_{\alpha}}{\mathrm{d} \widehat{w}}<0 \Leftrightarrow \eta_{<}^{>} \frac{(1-x) \alpha(1-\theta) \theta^{\alpha-1}+x^{\alpha}(1-\theta)(2 \theta-1)^{\alpha-1}}{\left[x \theta^{\alpha}+(1-x)\left(1-\theta^{\alpha}\right)-x(2 \theta-1)^{\alpha}\right]} .
$$

Once again, labor demand has to be sufficiently elastic (inelastic) for poverty to increase (decrease) when the minimum wage rises.

To sum up, in this section, we have analyzed the family sharing model. We have found instances in which a higher minimum wage necessarily increases poverty, instances in which a higher minimum wage may reduce poverty, and one instance in which poverty is necessarily unchanged. We have also demonstrated when each result arises as a function of how high the minimum wage $\widehat{w}$ is relative to the poverty line $z$, the elasticity of demand for labor $\eta$, and the poverty aversion parameter $\alpha$. 


\section{5 biscussion and conclusion}

A standard result in labor economics is that a higher minimum wage reduces employment. In the standard single-sector labor market model, reduced employment results in higher unemployment. The expected increase in unemployment leads many analysts to worry about the adverse effects of minimum wages or even to oppose them outright. Certainly if unemployment is equated with poverty, then this translates into a concern that a higher minimum wage would increase poverty. On the other hand, many trade unions argue that a higher minimum wage reduces poverty through raising incomes of the working poor and, even in cases where the employed are not all poor, through income sharing between the employed and the unemployed.

The results of this paper lead us to a more nuanced view about minimum wages than is commonly found in the literature. A higher minimum wage does not necessarily increase poverty because of the unemployment it creates. On the other hand, a higher minimum wage does not necessarily reduce poverty simply because it might increase total labor income, and some of this increased income is shared with the unemployed, either through family sharing or through social sharing. Thus the "standard labor economist's view" and the "standard trade unionist's view" are both simplistic. Not only does the truth lie somewhere in between, but it can be characterized precisely in terms of empirically observable parameters.

We have shown how the poverty effects of a minimum wage increase depends on four parameters: how high the minimum wage is relative to the poverty line, how elastic the demand for labor is, how much income-sharing takes place, and how sensitive the poverty measure is to the depth of poverty. The results of this paper, summarized in Table I, give the precise conditions under which a higher minimum wage raises poverty, a higher minimum wage lowers poverty, and a higher minimum wage leaves poverty unchanged. The implication for policy is that in order to be able to reach a judgment about whether a minimum wage would make things better or worse in poverty terms in a given setting, the analyst must know the values of these parameters.

The analysis presented in this paper may be extended to incorporate heterogeneous workers, multiple employment sectors, variations in household size and composition, endogenous labor force participation decisions, and partial income sharing within the family. Our basic point will certainly remain: that the simple policy views found in the literature are far too simplistic.

\section{References}

1. Adams, S., Neumark, D.: The effects of living wage laws: Evidence from failed and derailed living wage campaigns. J. Urban Fcon. 58(2), 177-202 (2005)

2. Brown, C.: Minimum wages, employment, and the distribution of income. In: Ashenfelter, O., Card, D. (eds.) Handbook of Labor Economics. Amsterdam, North Holland (1999)

3. Burkhauser, R.V., Couch, K.A., Wittenburg, D.C.: Who gets what from minimum wage hikes: a reestimation of Card and Krueger's distributional analysis. Ind. Labor Relat. Rev. 52(3), 547-552 (1996)

4. Card, D., Krueger, A.B.: Myth and Measurement: The New Economics of the Minimum Wage. Princeton University Press, Princeton, NJ (1995)

5. Card, D., Krueger, A.B.: Minimum wages and employment: a case study of the fast-food industry in New Jersey and Pennsylvania: reply. Am. Econ. Rev. 90(5), 1397-1420 (2000)

6. Ehrenberg, R.G., Smith, R.S.: Modern Labor Economics, 9 th edition. Addison Wesley, Boston (2006)

7. Fields, G.S.: Wage floors and unemployment: a two-sector analysis. Labour Econ. 4(1), 85-91 (1997)

8. Foster, J., Greer, J., Thorbecke, E.: A class of decomposable poverty measures. Econometrica 52(3), $761-776(1984)$

$-$ 
y. Freeman, K.: I the minimum wage as a redistributrve tool. Econ. J. 106, 65y-04y (1946)

10. Gramlich, E.M.: The impact of minimum wages on other wages, employment, and family incomes. Brookings Pap. Econ. Act. 2(76), 409-451 (1976)

11. Hamermesh, D.: Labor Demand. Princeton University Press, Princeton (1993)

12. Harris, J.R., Todaro, M.P.: Migration, unemployment, and development: a two sector analysis. Am. Econ. Rev. 60(1), 126-142 (1970)

13. Klasen, S., Woolard, I.: Surviving unemployment without state support: unemployment and household formation in South Africa. CEFifo Working paper no. 533 (2001)

14. McLeod, D., Lustig, N.: Minimum wages and poverty in developing countries: some empirical evidence. Brookings discussion papers in economics, no. 125. The Brookings Institution, Washington, DC (1996)

15. Mincer, J.: Unemployment effects of minimum wage. J. Polit. Econ. 84(4) Part Two, S87-S104 (1976)

16. Mincer, J.: The economics of wage floors. In: Ehrenberg, R.G. (ed.) Research in Labor Economics, vol. 6. JAI, Greenwich, CT (1984)

17. Morley, S.: Structural adjustment and the determinants of poverty in Latin America. In: Lustig, N. (ed.) Coping with Austerity: Poverty and Inequality in Latin America. Brookings Institution, Washington, DC (1995)

18. Neumark, D., Cunningham, W., Siga, L.: The effects of the minimum wage in Brazil on the distribution of family incomes: 1996-2001. J. Dev. Econ. 80(1), 136 159 (2006)

19. Neumark, D., Wascher, W.: Minimum wages and employment: a case study of the fast-food industry in New Jersey and Pennsylvania: comment. Am. Econ. Rev. 90(5), 1362-1396 (2000)

20. Neumark, D., Wascher, W.: Do minimum wages fight poverty? Exon. Inq. 40(3), 315-333 (2002) 